\title{
PENGGUNAAN RUMUS BANACHIEWICZ-SCHUR YANG DIPERUMUM DALAM PENENTUAN INVERS DIPERUMUM MATRIKS PARTISI
}

\author{
SRI WAHYUNI, YANITA, NOVA NOLIZA BAKAR \\ Program Studi S1 Matematika, \\ Fakultas Matematika dan Ilmu Pengetahuan Alam, Universitas Andalas, \\ Kampus UNAND Limau Manis Padang, Indonesia. \\ email : ssriwahyuniii@gmail.com,yanita@sci.unand.ac.id,novanoliza@sci.unand.ac.id
}

Diterima 17 Februari 2020 Direvisi 7 Maret 2020 Dipublikasikan 29 April 2020

\begin{abstract}
Abstrak. Penelitian ini membahas tentang penentuan rumus Banachiewicz-Schur yang diperumum dalam menentukan invers diperumum matriks partisi. Untuk Menentukan invers diperumum matriks partisi, maka akan ditentukan $\{1\}$-invers dan $\{1,2\}$-invers dari suatu matriks. Untuk menentukan $\{1\}$-invers dan $\{1,2\}$-invers dari suatu matriks, maka dapat ditentukan dengan beberapa cara yaitu dengan menggunakan invers kiri, invers kanan, faktorisasi full rank, bentuk normal Hermite.
\end{abstract}

Kata Kunci: Matriks partisi, rumus Banachiewicz-Schur, invers Moore-Penrose

\section{Pendahuluan}

Matriks merupakan susunan dari bilangan yang berbentuk persegi panjang yang terdiri dari baris dan kolom. Adapun salah satu dari perhitungan pada matriks adalah menentukan invers matriks. Invers matriks banyak digunakan dalam berbagai bidang seperti: ekonomi, statistik, pendidikan, manajemen, dan bidang teknologi.

Invers dari suatu matriks bujur sangkar secara umum ditentukan keberadaannya dengan menghitung determinan matriks tersebut. Jika determinan matriks tersebut tidak sama dengan nol, maka dikatakan matriks tersebut dapat dibalik atau memiliki invers. Untuk matriks-matriks yang berukuran $m \times n$ atau $n \times n$ yang determinannya sama dengan nol, tentu saja tidak memiliki invers. Akan tetapi matriks seperti ini dapat memiliki invers yang dinamakan invers diperumum.

Penentuan invers diperumum dari suatu matriks dapat dilakukan dengan berbagai macam cara, diantaranya: eliminasi Gauss [1], metode Ben-Nobble [6], dan faktor Full Rank [7]. Sementara untuk pehitungan invers diperumum, dengan menggunakan partisi matriks telah dijelaskan pada [4] dan [8], kemudian [5] menggabungkan teori dari [4] dan [8] dengan cara menggunakan rumus Banachiewicz-Schur pada

${ }^{*}$ penulis korespondensi 
100 Sri Wahyuni dkk

matriks yang dipartisi. Penelitian ini mengulas kembali apa yang ditulis pada [5], yaitu menentukan invers matriks partisi yang tidak invertibel dengan menggunakan rumus Banachiewicz-Schur.

\section{Landasan Teori}

\subsection{Matriks dan Operasi Matriks}

2.1.1. Matriks Elementer dan Matriks Permutasi

Definisi 2.1. [1] Matriks elementer adalah matriks yang diperoleh dari ope-rasi baris elementer yang tunggal pada matriks identitas $I_{m}$.

Definisi 2.2. [7] Misalkan $\sigma$ adalah permutasi. Didefinisikan matriks permutasi $P(\sigma)=\left[\delta_{i, \sigma(j)}\right]$ dimana $\delta_{i, \sigma(j)}$ bernilai 1 jika $i=\sigma(j)$ dan 0 jika $i \neq \sigma(j)$.

\subsubsection{Matriks Partisi}

Definisi 2.3. [1] Matriks paritisi adalah matriks yang dipartisi menjadi beberapa matriks yang ukurannya lebih kecil dengan memasukkan garis horizontal dan garis vertikal antara baris dan kolom matriks. Matriks-matriks kecil hasil partisi disebut submatriks.

\subsection{Bentuk Normal Hermite}

Definisi 2.4. [2] Suatu Matriks $H \in \mathbb{C}_{m \times n}$ dengan $r k(H)=r$, dikatakan bentuk normal Hermite jika:

(1) $r$ baris pertama memuat setidaknya satu elemen bukan nol, baris lainnya hanya berisi angka nol.

(2) terdapat $r$ bilangan bulat $1 \leq c_{1} \leq c_{2} \leq \cdots \leq c_{r} \leq n$, sedemikin sehingga elemen bukan nol pertama pada baris $i=12, \cdots, r$, muncul pada kolom $c_{i}$.

(3) semua elemen lainnya pada kolom $c_{i}$ adalah nol, $i=1,2, \cdots, r$.

Semua matriks $A \in \mathbb{C}_{m \times n}$ dengan $r k(A)=r$ dapat disederhanakan ke dalam bentuk normal Hermite

$$
E A P=\left[\begin{array}{cc}
I_{r} & K \\
0_{(m-n) \times r} & 0_{(m-r) \times(n-r)}
\end{array}\right] .
$$

\subsection{Invers Matriks}

Definisi 2.5. [7] Jika $A$ adalah matriks bujursangkar, dan jika terdapat ma-triks $B$ yang ukurannya sama sedemikian sehingga $A B=B A=I$, maka $A$ dapat dibalik dan $B$ disebut sebagai invers dari A. Jika matriks $B$ tidak dapat didefinisikan, maka A dinyatakan sebagai matriks singular.

Definisi 2.6. [7] Misalkan matriks A matriks berukuran $m \times n$. Matriks B berukuran $n \times m$ dikatan invers kiri dari $A$ jika $B A=I_{n}$ matriks $C$ dengan ukuran $n \times m$ dikatan invers kanan dari $A$ jika $A C=I_{m}$. 
Teorema 2.7. Misalkan $A \in \mathbb{C}_{m \times n}$ mempunyai invers kanan jika dan hanya jika $A$ adalah full-rank baris $m$ dan mempunyai invers kiri jika dan hanya jika $A$ adalah full-rank kolom $n$.

Definisi 2.8. [7] Misal $A \in \mathbb{C}_{m \times n}$ dikatakan mempunyai invers Moore-Penrose jika dan hanya jika terdapat suatu matriks $X \in \mathbb{C}_{n \times m}$ sedemikian sehingga memenuhi :

$$
\begin{aligned}
A X A & =A \\
X A X & =X \\
(A X)^{*} & =A X \\
(X A)^{*} & =X A
\end{aligned}
$$

Matriks $X$ pada definisi diatas ditulis sebagai $A^{+}$

Definisi 2.9. [7] Misalkan $A \in \mathbb{C}_{m \times n}$ dan $X \in \mathbb{C}_{n \times m}$.

(1) Matriks $X$ disebut $\{1\}$-invers dari matriks A jika memenuhi persamaan (2.1) dari invers Moore-Penrose dan selanjutnya dinotasikan dengan $X \in A\{1\}$ atau $A^{(1)}$.

(2) Matriks $X$ disebut $\{1,2\}$-invers dari matriks A jika memenuhi persamaan (2.1) dan (2.2) dari invers Moore-Penrose yang dinotasikan dengan $X \in A\{1,2\}$ atau $A^{(1,2)}$.

(3) Matriks $X$ disebut $\{1,2,3\}$-invers dari matriks A jika memenuhi persamaan (2.1), (2.2) dan (2.3) ketiga dari invers Moore-Penrose yang dinotasikan dengan $X \in A\{1,2,3\}$ atau $A^{(1,2,3)}$.

(4) Matriks $X$ disebut $\{1,2,4\}$-invers dari matriks $A$ jika memenuhi persamaan (2.1), (2.2) dan (2.4) dari invers Moore-Penrose yang dinotasikan dengan $X \in$ $A\{1,2,4\}$ atau $A^{(1,2,4)}$.

(5) Matriks $X$ disebut $\{1,2,3,4\}$-invers dari matriks $A$ jika memenuhi persamaan (2.1), (2.2), (2.3) dan (2.4) dari invers Moore-Penrose yang dinotasikan dengan $X \in A\{1,2,3,4\}$ atau $A^{(1,2,3,4)}$.

Definisi 2.10. [7] Misalkan $A \in \mathbb{C}_{m \times n}$, dimana $r>0$, jika kita dapat menemukan $F \in \mathbb{C}_{m \times r}$ dan $G \in \mathbb{C}_{r \times n}$ sehingga $A=F G$ maka kita katakan bahwa kita memiliki faktorisasi full rank dari $A \in \mathbb{C}_{m \times n}$.

Definisi 2.11. [7] Misalkan $A \in \mathbb{C}_{m \times n}$ dengan rank $A$ adalah $r>0$ dan $A$ mempunyai faktorisasi full rank $A=F G$ maka $F^{+}$dan $G^{+}$ada. Didefinisikan $A^{+} \in \mathbb{C}_{n \times m}$ dengan $A^{+}=F^{+} G^{+}$, jadi $A^{+}=G^{*}\left(G G^{*}\right)^{-1}\left(F^{*} F\right)^{-1} F^{*}$.

\subsection{Eksistensi dan Konstruksi $\{1\}$-Invers dan $\{1,2\}$-Invers yang Diperumum}

Teorema 2.12. Misalkan $A \in \mathbb{C}_{m \times n}$ dengan $r k(A)=r, E \in \mathbb{C}_{m \times m}$ dan $P \in \mathbb{C}_{n \times n}$ adalah matriks nonsingular sehingga,

$$
E A P=\left[\begin{array}{cc}
I_{r} & K \\
0_{(m-r) \times r} & 0_{(m-r) \times(n-r)}
\end{array}\right]
$$


102 Sri Wahyuni dkk

dimana $K \in \mathbb{C}_{r \times(n-r)}$, maka $\{1\}$-Invers dari $A \in \mathbb{C}_{m \times n}$ yaitu:

$$
G=P\left[\begin{array}{cc}
I_{r} & 0_{r \times(m-r)} \\
0_{(n-r) \times r} & L
\end{array}\right] E
$$

dengan $L \in \mathbb{C}_{(n-r) \times(m-r)}$.

Teorema 2.13. Misalkan matriks $A \in \mathbb{C}_{m \times n}$ dengan $r k(A)=r$, dan $G \in A\{1,2\}$ Invers dimana $r k(G)=r k(A)$, maka

$$
G=P\left[\begin{array}{cc}
I_{r} & 0_{r \times(m-r)} \\
0_{(n-r) \times r} & 0_{(n-r) \times(m-r)}
\end{array}\right] E
$$

untuk suatu $E \in \mathbb{C} m \times m$ dan $P \in \mathbb{C}_{n \times n}$ adalah matriks nonsingular.

\subsection{Komplemen Schur dan Rumus Invers Banachiewicz}

\section{Definisi 2.14.}

(1) Misalkan $M \in \mathbb{C}_{(n+p) \times(n+q)}$ adalah matriks yang dipartisi

$$
M=\left[\begin{array}{ll}
A & B \\
C & D
\end{array}\right] .
$$

Didefinisikan komplemen schur dari $A$ di $M$ dengan $S=D-C A^{-1} B$, dimana A invertibel.

(2) Misalkan $M \in \mathbb{C}_{(m+p) \times(n+p)}$ adalah matriks yang dipartisi

$$
M=\left[\begin{array}{ll}
A & B \\
C & D
\end{array}\right] .
$$

Didefinisikan komplemen schur dari $D$ di $M$ dengan $T=A-B D^{-1} C$, dimana $D$ invertibel.

Teorema 2.15. [7] Misalkan M matriks partisi, yaitu:

$$
M=\left[\begin{array}{ll}
A & B \\
C & D
\end{array}\right]
$$

(1) Jika $A^{-1}$ dan $S^{-1}$ ada, maka matriks $M$ adalah invertibel, sehingga

$$
M^{-1}=\left[\begin{array}{cc}
A^{-1}+A^{-1} B S^{-1} C A^{-1}-A^{-1} B S^{-1} \\
-S^{-1} C A^{-1} & S^{-1}
\end{array}\right] .
$$

(2) Jika $D^{-1}$ dan $T^{-1}$ ada, maka matriks $M$ adalah invertibel, sehingga

$$
M^{-1}=\left[\begin{array}{cc}
T^{-1} & -T^{-1} B D^{-1} \\
-D^{-1} C T^{-1} & D^{-1}+D^{-1} C T^{-1} B D^{-1}
\end{array}\right] .
$$




\section{Pembahasan}

Misalkan $M \in \mathbb{C}_{(m+p) \times(n+q)}$ adalah matriks yang dipartisi

$$
M=\left[\begin{array}{ll}
A & B \\
C & D
\end{array}\right],
$$

$S=D-C G B$, dimana $G$ adalah invers Moore-Penrose dari matiks $A$ yang memenuhi persamaan pada definisi (2.8) yaitu $\{1\}$-invers dan $\{1,2\}$-invers atau $G \in A\{1\}$ dan $G \in A\{1,2\}$.

$N$ adalah matriks partisi yang memiliki struktur spesifik dari rumus BanachiewiczSchur yang diperumum, yaitu:

$$
N=\left[\begin{array}{cc}
G+G B H C G-G B H \\
-H C G & H
\end{array}\right],
$$

dimana $H$ adalah invers Moore-Penrose dari matriks $S$ yang memenuhi persamaan pada definisi (2.8) yaitu $\{1\}$-invers dan $\{1,2\}$-invers atau $H \in S\{1\}$ dan $H \in$ $S\{1,2\}$.

$E_{A}=I_{n}-G A, F_{A}=I_{m}-A G, E_{S}=I_{q}-H S, F_{S}=I_{p}-S H$.

Sehingga,

$$
M N=\left[\begin{array}{cc}
A G-F_{A} B H C G & F_{A} B H \\
F_{S} C G & S H
\end{array}\right]
$$

dan

$$
N M=\left[\begin{array}{cc}
G A-G B H C E_{A} & G B E_{S} \\
H C E_{A} & H S
\end{array}\right] .
$$

Misalkan $M$ dan $N$ adalah matriks yang berukuran $2 \times 2$ maka:

(1) Baris pertama matriks $M$ dikalikan dengan kolom pertama matriks $N$ disimbolkan dengan $N W$ (North West).

(2) Baris pertama matriks $M$ dikalikan dengan kolom kedua matriks $N$ disimbolkan dengan $N E$ (North East).

(3) Baris kedua matriks $M$ dikalikan dengan kolom pertama matriks $N$ disimbolkan dengan $S W$ (South West).

(4) dan untuk baris kedua matriks $M$ dikalikan dengan kolom kedua matriks $N$ disimbolkan dengan $S E$ (South East).

Teorema 3.1. [5] Misalkan $M \in \mathbb{C}_{(m+p) \times(n+q)}$ adalah matriks partisi.

$$
M=\left[\begin{array}{cc}
A & B \\
C & D
\end{array}\right]
$$

$S=D-C G B$

$$
N=\left[\begin{array}{cc}
G+G B H C G & -G B H \\
-H C G & H
\end{array}\right],
$$

$E_{A}=I_{n}-G A, F_{A}=I_{m}-A G, E_{S}=I_{q}-H S, F_{S}=I_{p}-S H$ maka, $N \in$ $M\{1\}$ jika dan hanya jika $G \in A\{1\}, H \in S\{1\}, F_{A} B E_{S}=0, F_{S} C E_{A}=\boldsymbol{O}$, $F_{A} B H C E_{A}=\boldsymbol{O}$. 
104 Sri Wahyuni dkk

Bukti. Pada $S=D-C G B$ dan $E_{A}=I_{n}-G A, F_{A}=I_{m}-A G, E_{S}=I_{q}-H S, E_{S}=$ $I_{q}-S H$ maka dari

$$
M N=\left[\begin{array}{cc}
A G-F_{A} B H C G & F_{A} B H \\
F_{S} C G & S H
\end{array}\right] \text { dan } M=\left[\begin{array}{cc}
A & B \\
C & D
\end{array}\right] .
$$

Perhatikan bahwa,

$$
\begin{aligned}
(M N M)_{N W} & =\left(A G-F_{A} B H C G\right) A+\left(F_{A} B H\right) C \\
& =A G A-F_{A} B H C G A+F_{A} B H C \\
& =A+F_{A} B H C E_{A}, \\
(M N M)_{N E} & =\left(A G-F_{A} B H C G\right) B+\left(F_{A} B H\right) D \\
& =A G B+F_{A} B H S \\
& =B-F_{A} B E_{S}, \\
(M N M)_{S W} & =\left(F_{S} C G\right) A+(S H) C \\
& =C G A-S H C G A+S H C \\
& =C-F_{S} C E_{A}, \\
(M N M)_{S E} & =\left(F_{S} C G\right) B+(S H) D \\
& =F_{S} C G B+S H D \\
& =C G B+S H S .
\end{aligned}
$$

Akibatnya pada Definisi (2.8), $N \in M\{1\}$, yaitu:

jika dan hanya jika,

$$
M N M=M=\left[\begin{array}{ll}
A & B \\
C & D
\end{array}\right]
$$

$$
\begin{aligned}
(M N M)_{N W} & \Longleftrightarrow\left(A G-F_{A} B H C G\right) A+\left(F_{A} B H\right) C=M_{N W}=A \\
& \Longleftrightarrow A+F_{A} B H C E_{A}=A \\
& \Longleftrightarrow F_{A} B E_{S}=\mathbf{0}, \\
(M N M)_{S W} & \Longleftrightarrow\left(F_{S} C G\right) A+(S H) C=M_{S W}=C \\
& \Longleftrightarrow C G A+S H C E_{A}=C \\
& \Longleftrightarrow F_{S} C E_{A}=\mathbf{0} \\
(M N M)_{S E} & \Longleftrightarrow\left(F_{S} C G\right) B+(S H) D=M_{S E}=D \\
& \Longleftrightarrow S H S=D-C G B \\
& \Longleftrightarrow S H S=S .
\end{aligned}
$$

Teorema 3.2. [5] Misalkan $M \in \mathbb{C}_{(m+p) \times(n+q)}$ adalah matriks partisi

$$
M=\left[\begin{array}{ll}
A & B \\
C & D
\end{array}\right], S=D-C G B, N=\left[\begin{array}{cc}
G+G B H C G-G B H \\
-H C G & H
\end{array}\right],
$$

$E_{A}=I_{n}-G A, F_{A}=I_{m}-A G, E_{S}=I_{q}-H S, F_{S}=I_{p}-S H$ maka, $N \in M\{2\}$ jika dan hanya jika $G \in A\{1,2\}$ dan $H \in S\{2\}$. 
Bukti. Pada $S=D-C G B$ dan $E_{A}=I_{n}-G A, F_{A}=I_{m}-A G, E_{S}=I_{q}-H S, E_{S}=$ $I_{q}-S H$ maka dari

$$
N M=\left[\begin{array}{cc}
G A-G B H C E_{A} & G B E_{S} \\
H C E_{A} & H S
\end{array}\right] \text { danN }=\left[\begin{array}{cc}
G+G B H C G-G B H \\
-H C G & H
\end{array}\right] .
$$

Berdasarkan pembuktian Teorema 3.1, kita temukan bahwa dengan notasi tambahan $H S H-H=Q$.

Perhatikan bahwa,

$$
\begin{aligned}
(N M N)_{N W} & =\left(G A-G B H C E_{A}\right)(G+G B H C G)-G B E_{S} H C G \\
& =G A G+G A G B H C G-G B\left(I_{n}-H S\right) H C G \\
& =G+G A G B H C G \\
(N M N)_{N E} & =\left(G A-G B H C E_{A}\right)(-G B H)+G B E_{S} H \\
& =-G B H+G B E_{S} H \\
& =-G B H \\
(N M N)_{S W} & =H C E_{A}(G+G B H C G)-H S H C G \\
& =H C E_{A} G+H C E_{A} G B H C G-H S H C G \\
& =-H C G \\
(N M N)_{S E} & =\left(H C E_{A}\right)(-G B H)+H S H \\
& =-Q+H S H \\
& =H .
\end{aligned}
$$

Akibatnya, $N \in M\{2\}$, yaitu:

$$
N M N=N=\left[\begin{array}{cc}
G+G B H C G-G B H \\
-H C G & H
\end{array}\right],
$$

jika dan hanya jika

$$
\begin{aligned}
(N M N)_{N W} & \Longleftrightarrow\left(G A-G B H C E_{A}\right)(G+G B H C G)-G B E_{S} H C G \\
& =N_{N W}=G+G B H C G \\
\Longleftrightarrow & \left(E_{A}+G B H C G E_{A}\right)(G+G B H C G)=G B Q C G \\
\Longleftrightarrow & E_{A}(G+G B H C G)=\mathbf{0}, \\
(N M N)_{N E} & \Longleftrightarrow\left(G A-G B H C E_{A}\right)(-G B H)+G B E_{S} H=N_{N E}=-G B H \\
\Longleftrightarrow & \left(E_{A}+G B H C E_{A}\right) G B H=-G B H+G B H S H \\
\Longleftrightarrow & E_{A} G B H=\mathbf{0}, \\
(N M N)_{S W} & \Longleftrightarrow H C E_{A}(G+G B H C G)-H S H C G=N_{S W}=-H C G \\
& \Longleftrightarrow H C E_{A}(G+G B H C G)=Q C G \\
& H C E_{A} G=\mathbf{0},
\end{aligned}
$$

$$
\begin{aligned}
(N M N)_{S E} & \Longleftrightarrow H C E_{A}(-G B H)+H S H=N_{S E}=H \\
& \Longleftrightarrow H C E_{A} G B H=H S H-H \\
& \Longleftrightarrow H C E_{A} G B H=Q .
\end{aligned}
$$


Subsitusi persamaan (3.2) ke persamaan (3.3)

$$
\begin{aligned}
& H C E_{A}(G+G B H C G)=Q C G \\
& H C E_{A}(G+G B H C G)=H C E_{A} G B H C G .
\end{aligned}
$$

\section{Kesimpulan}

Berdasarkan penelitian ini, rumus Banachiewicz-Schur sebelumnya digunakan untuk menentukan invers dari matriks parisi yang invertibel, tetapi rumus BanachiewiczSchur ini juga dapat digunakan untuk matriks partisi yang tidak invertibel, dimana entri-entri submatriksnya menggunakan $\{1\}$-invers dan $\{1,2\}$-invers, sehingga kesimpulan yang dapat diambil adalah penentuan invers matriks partisi yang diperumum dapat ditentukan dengan rumus:

$$
N=\left[\begin{array}{cc}
G+G B H C G-G B H \\
-H C G & H
\end{array}\right]
$$

dimana, $H$ adalah invers dari $S$ yaitu $S=D-C G B$,

(i) Jika $G \in A\{1\}, H \in S\{1\}$ maka $N \in M\{1\}$.

(ii) Jika $G \in A\{1,2\}, H \in S\{2\}$ maka $N \in M\{2\}$.

\section{Daftar Pustaka}

[1] Anton, H dan C. Rorres. 2000. Aljabar Linier Elementer (terjemahan); Edisi Kedelapan. Erlangga, Jakarta.

[2] Ben-Israel, A and T. N. E. Greville. 2003.Generalized Inverses Theory And Aplicatinon; Second Edition. Springer-Verlag New York, Inc, USA.

[3] Britz, T. 2007. The Moore Penrose Inverse. Electronic Journal of Linier Algebra. 6:208-215.

[4] G. Marsaglia, G. P. H. Styan. 1976. Rank Conditions for Generalized Inverses of Partitioned Matriks. Sankhya Ser. A. 36:437 - 442.

[5] J. K Baksalary and G. P. H. Styan. 2002. Generalized inverses of Partitioned Matrices in Banachiewicz-Schur Form. Linear Algebra and Its Applications. 354: $41-47$

[6] Noble, B. 1966. A Method For Computing The Generalized Inverses Of a Matrix. Vol 3, No.44. SIAM.

[7] Piziak, R and P. L Odell. 2007. Matriks Theory From Generalized Inverses to Jordan Form. Chapman and Hall/CRC, Canada.

[8] R. Penrose. 1955. A Generalized Inverse for Matrices. Proc. Cambridge Philos. Soc. 51: $406-413$.

[9] Searle, S. R. 1928. Matrix Algebra Useful For Statistics. New York State College Of Agriculture and Life Sciences Cornel University, New York. 